\title{
Induction cisplatin-irinotecan followed by concurrent cisplatin- irinotecan and radiotherapy without surgery in oesophageal cancer: multicenter phase II FFCD trial
}

\author{
P Michel I,*, A Adenis', F Di Fiore', E Boucher ${ }^{3}$, MP Galais ${ }^{4}$, L Dahan $^{5}$, X Mirabel $^{6}, \mathrm{H} \mathrm{Hamidou}^{7}, \mathrm{JL} \mathrm{Raoul}^{3}$, \\ JH Jacob ${ }^{4}$, MF Hellot ${ }^{8}$, S Prod'homme ${ }^{9}$ and B Paillot
}

'Unité d'oncologie digestive, Service d'Hepato-Gastroenterologie, CHU de Rouen, I rue de Germont 7603। Rouen Cedex, France; '2 Service d'Oncologie Medicale, Centre Oscar Lambret, 3 rue Frederic Combemale, BP307, 59020 Lille, France; ${ }^{3}$ Département d'Oncologie Medicale, Centre Regional de Lutte Contre le Cancer, Eugene Marquis, 35062 Rennes Cedex, France; ${ }^{4}$ Service d'Onclogie Digestive, Centre Regional de Lutte Contre le Cancer, Francois Baclesse, 3 avenue General Harris, 14076 Caen Cedex, France; ${ }^{5}$ Unité d'Oncologie Digestive, Service d'Hepato-Gastroentérologie, CHU Timone, 264 rue Saint-Pierre 13365 Marseille Cedex 5, France; ${ }^{6}$ Senvice de Radiotherapie, Centre Oscar Lambret, 3 rue Frederic Combemale, BP307, 59020 Lille, France; ${ }^{7}$ Service de Radiotherapie Centre Régional de Lutte Contre le Cancer, Henri Becquerel, rue d'Amiens, 76000 Rouen, France; ${ }^{8}$ Unité de Biostatistique, CHU de Rouen, I rue de Germont, 7603 I Rouen Cedex, France; 'Sabrina Prod'homme, Delegation à la Recherche Clinique, CHU de Rouen, I rue de Germont, 76031 Rouen Cedex, France

A recent phase I study showed that weekly cisplatin, irinotecan and concurrent radiotherapy can be administered with moderate toxicity in patients with oesophageal cancer. Patients with no prior treatment and oesophageal cancer stage I to III, performance status $<3$, caloric intake $>1500 \mathrm{kcal} \mathrm{day}^{-1}$ were included. Chemotherapy, with cisplatin $30 \mathrm{mg} \mathrm{m}^{-2}$ and irinotecan $60 \mathrm{mg} \mathrm{m}^{-2}$, was administered at days I, 8, 22, 29, and concurrently with radiotherapy at days 43, 50, 64 and 7I. Radiotherapy was delivered with 50 or 50.4 Gy in 25 fractions/5 weeks. Forty-three patients were included, 10 stage I, I 9 stage II and I 4 stage III. Mean age was 59.2 years (range 44-79). A total of 30 out of 43 (69.8\%) patients underwent all planned treatment. During induction chemotherapy, 14 severe toxicities of grade 3 or 4 in 10 patients (23.3\%) were reported with $57.1 \%$ due to haematoxicity. During chemoradiotherapy, 31 severe toxicities of grade 3 or 4 with $64.5 \%$ due to haematotoxicity were reported in 18 patients. One toxic death occurred (diarrhoea grade 4). The complete clinical response rate was 58. I\% (95\% Cl: 43.4-72.8\%). Overall survival rate at I and 2 years was $62.8 \%,(95 \% \mathrm{Cl}, 58.3-77.3 \%)$ and $27.9 \%$ (95\% Cl, 13.4-41.3\%), respectively. In conclusion, cisplatin-irinotecan-radiotherapy is an active and well-tolerated regimen feasible in out-patients.

British Journal of Cancer (2006) 95, 705-709. doi: I0.1038/sj.bjc.6603328 www.bjcancer.com

(c) 2006 Cancer Research UK

Keywords: oesophageal cancer; exclusive chemo-radiotherapy; induction chemotherapy

Oesophageal cancer is an aggressive disease with a poor prognosis (Enzinger and Mayer, 2003). In the USA and Europe the number of new cases per year is 13100 and 34300 , respectively (Jemal et al, 2002; Keighley, 2003). At the time of the diagnosis, more than $50 \%$ of patients have inoperable disease. In these patients, the more effective treatment in locally advanced disease is chemo-radiotherapy (Enzinger and Mayer, 2003). Moreover, in operable patients with locally advanced oesophageal cancer, the combination of chemotherapy and concurrent radiotherapy has been demonstrated to have an outcome similar to that of surgery after preoperative therapy (Bedenne et al, 2002; Stahl et al, 2005). The standard chemotherapy regimen associates 5 Fluorouracil (FU) with cisplatin (Herskovic et al, 1992; Cooper et al, 1999)

\section{*Correspondence: Professor P Michel;}

E-mail: pierre.michel@chu-rouen.fr

This work was presented in part at the 4 Ist Annual Meeting of the American Society of Clinical Oncology, Orlando, FL, May 13-17, 2005. Received 24 May 2006; revised 24 July 2006; accepted 25 July 2006 and the recommended total dose of concurrent radiation is $50 \mathrm{~Gy}$ (Minsky et al, 2002). A number of drugs have been tested in oesophageal cancer (Enzinger et al, 1999; Geh, 2002). Recent trials combining weekly irinotecan with cisplatin have reported a response rate exceeding 50\% (Ilson et al, 1999; Ajani et al, 2002). The active metabolite of irinotecan (SN38) increases the proportion of cells in the $\mathrm{G} 2-\mathrm{M}$ or $\mathrm{M}$ phase. These phases are the most radiosensitive of the cycle (Tamura et al, 1997). Phase I-II studies of weekly irinotecan and radiation therapy have been performed (Koukourakis et al, 1999; Takeda et al, 1999). Recently, phase I study of weekly with cisplatin-irinotecan chemotherapy followed by chemo-radiotherapy in locally advanced oesophageal cancer has been reported (Ilson et al, 2003). The dose-limiting toxicity was primarily myelosuppression, no grade 3 or 4 oesophagitis, diarrhoea or stomatitis was observed.

In the current multicentre phase II trial, our aim was to evaluate the efficacy and toxicity of cisplatin-irinotecan chemotherapy followed with chemo-radiotherapy as definitive treatment in patients with oesophageal cancer. 


\section{PATIENTS AND METHODS}

\section{Patient eligibility}

All patients had histologically confirmed squamous cell carcinoma, adenocarcinoma or poorly differentiated non-small-cell carcinoma of the oesophagus. Participants were required to be at least 18 years of age and to provide written informed consent prior to treatment. Patients had an Eastern Cooperative Oncology Group (ecog) performance status $\leqslant 2$ (Karnofsky performance status of $70 \%$ or greater), caloric intake $>1500 \mathrm{kcal} \mathrm{d}^{-1}$, serum albumin $\geqslant 32 \mathrm{gl}^{-1}$ and adequate haematological, renal, and hepatic function as defined by an absolute neutrophil count $\geqslant 1.5 \times 10^{9} 1^{-1}$, platelets $\geqslant 100 \times 10^{9} 1^{-1}$, serum creatinine $\leqslant 120 \mu \mathrm{moll}^{-1}$ and total serum bilirubin $\leqslant 1.5 \mathrm{mg} \mathrm{dl}^{-1}$. Patients had no prior chemotherapy, radiotherapy or surgery. Patients with metastatic disease to supraclavicular or metastatic disease with biopsy-proven tumour invasion of the tracheobronchial tree or with tracheoesophageal fistula were not included. Patients with severe comorbid conditions, including cardiac disease graded as New York Heart Association class 3 or 4, or myocardial infarction within the previous 6 months were also excluded. Also patients with a prior history of malignancy, other than basal cell carcinoma of the skin, in situ cervical carcinoma, or head and neck carcinoma with complete response since 3 years of inclusion of the study were also not included. Patients with known Gilbert's syndrome were not included.

\section{Pretreatment evaluation and evaluation on study}

Pretreatment evaluation included a detailed medical history and physical examination, a complete blood count, biochemical screening profile including liver function assessment and electrolytes, a prothrombin time and ECG. Radiologic evaluation included a CT scan of the chest and abdomen. Patients were required to undergo endoscopy with biopsy of the primary tumour. Endoscopy with ultrasonography (EUS) was optional. Bronchoscopy was performed in patients with tumours of the cervical or proximal thoracic oesophagus and in patients with squamous cell carcinoma. The 1983 AJCC staging system (Table 1) was used in this study according to published recommendations (Coia et al, 2000). Patients were examined the morning prior to each chemotherapy infusion during induction chemotherapy and combined chemoradiotherapy. At 10-12 weeks after completion of therapy, an upper endoscopy with biopsy, and a CT scan were repeated to assess response. Clinical complete response was defined as no tumour detectable on oesophagus endoscopy and no appearance of lymph nodes or distant metastasis on CT scan (Kelsen et al, 1983; Jones et al, 1999). In all other cases, the patients were considered in the absence of response. Surgery was not mandated on protocol. When patients achieved a complete clinical response, immediate follow-up was carriedout at the discretion of the investigator. Upper endoscopy and CT scan of the chest and abdomen were performed annually. Dysphagia was evaluated prior to therapy and after completion of induction chemotherapy using a previously

Table I The 1983 AJCC staging system for oesophageal cancer

\begin{tabular}{ll}
\hline Stage & Criterion \\
\hline II & $<5 \mathrm{~cm}$ in length, nonobstructing, noncircumferential \\
III & $\begin{array}{l}\text { Evidence of extra oesophageal spread (computed tomography } \\
\text { scan indicating invasion of surrounding structures or clinical evidence } \\
\text { such, as recurrent laryngeal nerve involvement, positive pleural effusion, } \\
\text { tracheoesophageal fistula, sympathetic nerve involvement, phrenic nerve } \\
\text { involvement or widened mediastinum on chest radiograph) }\end{array}$ \\
\hline
\end{tabular}

published dysphagia scale (Ogilvie et al, 1982). All toxicity was graded using the National Cancer Institute Common Toxicity Criteria version 2.0 .

\section{Treatment plan}

The treatment procedure is outlined in Figure 1. Therapy was delivered in two phases: four induction chemotherapy courses were administered on days 1, 8, 22, 29 with the third and sixth week used as rest weeks. Four chemotherapy courses concurrent with radiotherapy (courses 5 to 8 ) were administered days 43,50 , 64 and 71 with the ninth week used as a rest week. Antiemetic therapy, with steroid and 5-HT3 receptor antagonist was recommended. Hydration with $500 \mathrm{ml}$ of intravenous fluid was performed before cisplatin at a dose of $30 \mathrm{mg} \mathrm{m}^{-2}$ as a $30-\mathrm{min}$ infusion. After cisplatin, irinotecan was administered at a dose of $60 \mathrm{mg} \mathrm{m}^{-2}$ as a 30 -min infusion. As required, atropine $0.5 \mathrm{mg}$ was given to patients who developed abdominal cramps or diarrhoea within $1 \mathrm{~h}$ of irinotecan infusion. Written information regarding the treatment of diarrhoea as delayed toxicity was routinely given at the first chemotherapy. All diarrhoeas were treated by loperamide. To continue induction chemotherapy, patients were required to maintain a $\mathrm{WBC} \geqslant 3.0 \times 10^{9} 1^{-1}$, absolute neutrophil count $\geqslant 1.5 \times 10^{9} 1^{-1}$, platelet count $\geqslant 100 \times 10^{9} 1^{-1}$, serum creatinine $\leqslant 120 \mu \mathrm{gl}^{-1}$ and diarrhoea toxicity $\leqslant$ grade 2 . No prophylactic use of granulocyte colony-stimulating factor was planned.

\section{Radiation therapy}

Radiation therapy was delivered with megavoltage equipment using a multiple-field technique. Patients were treated 5 days per week at 1.8 or $2 \mathrm{~Gy} \mathrm{day}^{-1}$ to a total dose of 50.4 or $50.0 \mathrm{~Gy}$. All fields were treated each day. Treatment was delivered to three or four fields (anterior-posterior/posterior-anterior and opposed laterals) in order that the dose did not vary by more than $5 \%$ over the entire target volume. The prescribed total dose was prescribed at the reference point (isocentre) of the PTV, which covered the volume at risk. The upper and lower borders of the radiation field were $3-5 \mathrm{~cm}$ beyond the primary tumour. The lateral, anterior and posterior borders of the field were $\geqslant 2 \mathrm{~cm}$ beyond the borders of the primary tumour. The tumour size was defined by CT scan. The primary and regional lymph nodes were also included.

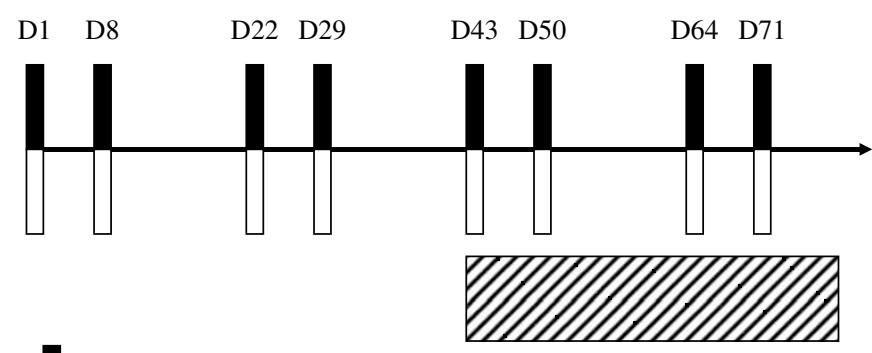

Cisplatin $30 \mathrm{mg} \mathrm{m}^{-2}$

Irinotecan $60 \mathrm{mg} \mathrm{m}^{-2}$

Radiotherapy, 50.4 Gy, $1.8 \mathrm{~Gy} \mathrm{day}^{-1}$

Figure I Treatment flow chart. 


\section{Statistical design}

The primary end point of the study was clinical complete response rate. The study was designed using a two-stage design (Bellisant et al, 1996). Assuming clinical complete response rate at $60 \%$ with alpha risk $5 \%$ and power $80 \%$, the number of patients necessary was calculated at 43 . In the first stage, 34 patients were accrued. If clinical complete response was observed in less than 17 patients, the trial was considered closed due to ineffectiveness of studied regimen. If more than 17 patients presented a complete clinical response, inclusion was continued to 43 patients. Analysis was performed in intent to treat. Quantitative data were presented as mean or median. Qualitative data were presented with frequency and percentage. The proportion of patients with clinical complete response was used to estimate the true response rate with a $95 \%$ confidence interval $(95 \% \mathrm{CI})$. Overall survival and survival without recurrence rate at 1 and 2 years was estimated. The dysphagia scale used had five stages (Ogilvie et al, 1982). For results analysis patients were pooled in two groups $(1-2,>2)$. Dysphagia prior to and after induction chemotherapy was compared. Then, relationship between dysphagia after induction chemotherapy and response was evaluated. These groups were compared using the Wilcoxon-Mann-Whitney test.

\section{RESULTS}

Between February 2003 and December 2003, 43 patients were included. Patient characteristics are listed in Table 2. Histological type was squamous cell carcinoma in 38 out of 43 patients $(88.4 \%)$. At the inclusion, 12 out of 43 patients $(27.9 \%)$ presented a severe

Table 2 Patient characteristics

\begin{tabular}{|c|c|}
\hline \multicolumn{2}{|l|}{$N=43$} \\
\hline Age in years (mean) & 59.2 yrs (60.9 yrs) \\
\hline Sex ratio & 30 males/4 females \\
\hline \multicolumn{2}{|l|}{ Histology n (\%) } \\
\hline Squamous cell carcinoma & $38(88.4 \%)$ \\
\hline Adenocarcinoma & $4(9.3 \%)$ \\
\hline Poor differenced & I $(2.3 \%)$ \\
\hline \multicolumn{2}{|l|}{ Tumour n (\%) } \\
\hline Proximal & $15(34.9 \%)$ \\
\hline Middle & $19(44.2 \%)$ \\
\hline Distal & $9(20.9 \%)$ \\
\hline \multicolumn{2}{|l|}{ Dysphagia (Atkinson score ): n (\%) } \\
\hline Grade $>2$ & $12(29.3 \%)$ \\
\hline \multicolumn{2}{|l|}{ Performance status ECOG: n (\%) } \\
\hline 0 & $17(39.5 \%)$ \\
\hline $1-2$ & $26(60.5 \%)$ \\
\hline \multicolumn{2}{|l|}{ Weight loss n (\%) } \\
\hline$<15 \%$ & $31(72.1 \%)$ \\
\hline$>15 \%$ & $12(27.9 \%)$ \\
\hline \multicolumn{2}{|l|}{ Tumour stage, UICC 1983: n (\%) } \\
\hline Stage I & $10(23.2 \%)$ \\
\hline Stage II & $19(44.2 \%)$ \\
\hline Stage III & $14(32.6 \%)$ \\
\hline Serum albumin (mean in $\mathrm{gl}^{-1}$ ) & $39.5 \mathrm{gl}^{-1}$ \\
\hline Tumour diameter (CT scan, median in $\mathrm{mm}$ ) & $34.5 \mathrm{~mm}$ \\
\hline \multicolumn{2}{|l|}{ Endoscopic Ultrasonography $(n=12)$} \\
\hline T3 & $9(75 \%)$ \\
\hline $\mathrm{N}+$ & $6(50 \%)$ \\
\hline MIa (celiac node) & | (8.3\%) \\
\hline
\end{tabular}

weight loss $(>15 \%)$ and 26 out of 43 patients $(60.5 \%)$, a moderate deterioration of performance status (ECOG 1).

\section{Treatment}

Of the 43 patients included, $30(69.8 \%)$ completed treatment as planned, 35 patients $(81.4 \%)$ completed the four cycles of induction chemotherapy and 34 patients $(79.1 \%)$ completed the total doses of radiation therapy. Radiotherapy with $2 \mathrm{~Gy}$ per fraction was performed in 31 patients $(79.5 \%)$. In eight patients, a radiotherapy protocol violation recorded with fractions number superior to 25 . The total dose was $56 \mathrm{~Gy}$ in $1,60 \mathrm{~Gy}$ in $4,62 \mathrm{~Gy}$ in 1 and $64 \mathrm{~Gy}$ in 1 . In eight patients (18.6\%) treatment was stopped due to toxicity (4 haematological, 4 nonhaematological). In four patients, treatment was stopped after cycle 7 due to nonadherence to protocol without toxic effect reported. One patient declined to undergo the last cycle of induction chemotherapy. During induction chemotherapy period, dose attenuation was required in less than $10 \%$ of patients: course 3 (cisplatin 1 patient, irinotecan 4 patients); course 4 (irinotecan 2 patients). Treatment delay occurred in 15 and $5.7 \%$ of patients, respectively, at course 3 and 4. The delay was due to haematological toxicity in $87.5 \%$ of cases. During chemo-radiotherapy period, dose attenuation was performed at courses 5, 6, 7 and 8, in 22.1, 23.0, 25.7 and $24.3 \%$ of patients for cisplatin and in $22.1,28.6,28.6$ and $30.3 \%$ of patients for irinotecan, respectively. Treatment delay occurred in 21.0, 20.0, 20.0 and $15.6 \%$ of patients, respectively, at courses $5,6,7$ and 8 . Treatment delay was due to haematological toxicity in 24 out of 27 $(88.9 \%)$ of cases, the other causes were dysphagia (2 patients) and deep thrombosis (one patient). The most common cause of dose attenuation was haematologic toxicity.

\section{Toxicity}

Toxicities observed during induction chemotherapy are listed in Table 3. During this period, 246 toxicities were reported with $56.9 \%$ due to haematoxcicity. Fourteen severe toxicities of grade 3 or 4 in 10 patients $(23.3 \%)$ were reported with $57.1 \%$ due to haematoxcicity. Hospitalisation was required in five patients during this period, due to deficient nutritional intake (two patients), myocardial infarction (one patient), severe diarrhoea (grade 4) (one patient) and tracheoesophageal fistula (one patient).

Toxicities observed during chemoradiotherapy are listed in Table 4. During this period, 311 toxicities were reported with $72.8 \%$ due to haematotoxicity. Thirty-one severe toxicities of grade 3 or 4 with $64.5 \%$ due to haematotoxicity were reported in 18 patients. During this period, no grade 3-4 alopecia was recorded. Only one deep thrombosis was observed. The other non-

Table 3 Toxicity episodes: induction chemotherapy

\begin{tabular}{lrrrr}
\hline & Grade I & Grade 2 & Grade 3 & Grade 4 \\
\hline Alopecia & 9 & 9 & 0 & 0 \\
Anaemia & 75 & 13 & 0 & 0 \\
Diarrhoea & 26 & 3 & 1 & 1 \\
Fever & 1 & 1 & 0 & 0 \\
Infection+neutropenia & 0 & 1 & 0 & 0 \\
Nausea-vomiting & 32 & 13 & 1 & 0 \\
Neutropenia & 22 & 11 & 6 & 1 \\
Febrile neutropenia & 0 & 4 & 0 & 0 \\
Mucositis & 6 & 0 & 0 & 0 \\
Thrombopenia & 5 & 1 & 1 & 0 \\
Deep thrombosis & 0 & 0 & 0 & 0 \\
Heart & 0 & 0 & 0 & 1 \\
Fatigue & 0 & 0 & 0 & 1 \\
Esotracheal fistula & - & - & - & 1 \\
\hline
\end{tabular}


Table 4 Toxicity episodes: combined chemoradiotherapy

\begin{tabular}{lcccc}
\hline & Grade I & Grade 2 & Grade 3 & Grade 4 \\
\hline Alopecia & 13 & 7 & 0 & 0 \\
Anaemia & 97 & 36 & 5 & 0 \\
Diarrhoea & 11 & 3 & 0 & 0 \\
Fever & 3 & 0 & 0 & 0 \\
Oesophagitis & & & & \\
Infection+neutropenia & 21 & 17 & 5 & 1 \\
Nausea-vomiting & 0 & 0 & 0 & 1 \\
Leuconeutropenia & 27 & 0 & 0 & 0 \\
Neutropenia and fever & 31 & 11 & 9 & 3 \\
Mucositis & 1 & 16 & 0 & 1 \\
Thrombopenia & 9 & 0 & 1 & 0 \\
Deep thrombosis & 13 & 2 & 2 & 0 \\
Heart & 0 & 0 & 1 & 0 \\
Sepsis & 0 & 0 & 1 & 0 \\
Kidney & 0 & 0 & 0 & 1 \\
Asthenia & 0 & 0 & 1 & 0 \\
M & 0 & 0 & 4 & 0 \\
\hline
\end{tabular}

a Oesophagitis defined by painful dysphagia and/or thoracic burning.

haematological toxicities were tachycardia (one), and common toxicities with chemotherapy (functional kidney failure: one, mucositis: one) and radiotherapy (dysphagia: two, asthenia: four). Seventeen hospitalisations in 13 patients were required. Hospitalisations were required for vomiting, dysphagia or oesophagitis (six), only biological disorders (seven), sepsis (one), asthenia (one) and deep thrombosis (one). One treatment-related death occurred: 4 days after the cycle 7 , patient 31 presented with a severe diarrhoea grade 4 with vomiting. This patient was hospitalised in the emergency ward. He developed aplasia and kidney failure, and later died from septic shock.

Severe adverse events were reported in 24 patients $(55.8 \%)$ during the treatment; $11(25.6 \%)$ and $13(30.2 \%)$ of patients during induction chemotherapy and chemo-radiotherapy, respectively.

\section{Response and survival}

Twenty-five of 43 included patients (58.1\%; 95\% CI, 43.4-72.8\%) achieved a complete clinical response. In 14 patients, the complete clinical response was defined by endoscopy with biopsy, in other patients only macroscopic characteristics were used. Thirteen patients $(30.2 \%$; 95\% CI, $16.5-43.9 \%)$ were in the absence of response as previously defined (i.e. partial response, stable disease or progression). Five patients were not available for response, as four patients discontinued treatment prior to radiotherapy and one patient died before evaluation. One patient was lost to followup after the first cycle of chemotherapy, the 42 other patients were followed-up at 2 years or to death. Overall survival rate at 1 and 2 years were $62.8 \%$ (95\% CI, 58.3-77.3\%) and $27.9 \%$ (95\% CI, $13.4-$ $41.3 \%)$, respectively. The disease free survival rate at 1 and 2 years was $23.2 \%$ (95\% CI, $10.6-35.8 \%$ ) and $16.7 \%$ (95\% CI, 5.6-27.8\%). Three patients underwent surgery during follow-up period for suspected local recurrence. In one case (i.e. poor differentiated tumour) oesophageal EUS performed 2 months after the treatment suggested a stable disease (uT3) when endoscopy was normal. The pathologic examination of the surgical specimen showed the absence of cancer cells and confirmed the clinical complete response. In the two other cases, local recurrence was confirmed by biopsies, in one patient the tumour was not resectable.

\section{Dysphagia}

Only 12 patients $(29.3 \%)$ had dysphagia (grade $>2$ ) prior to the treatment. After induction chemotherapy and chemo-radiotherapy, $15(38.5 \%)$ and $6(17.1 \%)$ patients, respectively,
Table 5 Dysphagia

\begin{tabular}{lccc}
\hline $\begin{array}{l}\text { Atkinson } \\
\text { score }\end{array}$ & $\begin{array}{c}\text { Before } \\
\text { treatment } \\
\mathbf{N}=\mathbf{4 I}\end{array}$ & $\begin{array}{c}\text { End of induction } \\
\text { chemotherapy } \\
\mathbf{N}=\mathbf{3 9}\end{array}$ & $\begin{array}{c}\text { End of } \\
\text { chemoradiotherapy } \\
\mathbf{N}=\mathbf{3 5}\end{array}$ \\
\hline 1 & 4 & $1 \mid$ & 16 \\
2 & 25 & 13 & 13 \\
3 & 8 & 8 & 2 \\
4 & 4 & 6 & 3 \\
5 & 0 & $\mid$ & 1 \\
\hline
\end{tabular}

experienced dysphagia (grade $>2$ ). The differences were not statistically significant with $P=0.565$ and 0.099 , respectively (Table 5). No significant correlation was found between dysphagia after induction chemotherapy and clinical response after the treatment $(P=0.797)$. The variation of weight during the treatment regimen was mean $-0.3 \mathrm{~kg}$ (range: +2 to $-13 \mathrm{~kg}$ ).

\section{DISCUSSION}

The present study is to our knowledge the first phase II trial evaluating in a population of inoperable patients with the regimen defined in phase I (Ilson et al, 2003). The main results of the present study were the complete clinical response rate of $58.1 \%$ (95\% CI, 43.4-72.8\%), overall survival rate of $27.9 \%$ (95\% CI: $13.4-41.3 \%)$ at 2 years and the absence of significant improvement of dysphagia after induction chemotherapy. Compliance was satisfactory in $69.8 \%$ patients who completed treatment as planned although a severe adverse event was reported in 24 patients $(55.8 \%)$.

The combination of weekly cisplatin-irinotecan in metastatic oesophageal cancer showed an objective response rate of $57 \%$ (Ilson et al, 1999). In the present study, the clinical complete response rate obtained with cisplatin - irinotecan and radiotherapy regimen was $58.1 \%$ (CI 95\%: $43.4-72.8 \%$ ), in a range similar to that reported with a $\mathrm{FU}$-cisplatin and radiotherapy regimen (Seitz et al, 1990; Poplin et al, 1996; Geh, 2002). The overall survival rate at 2 years of $27.9 \%$ (CI 95\%: $13.4-41.3 \%$ ) in our study was similar to the result of standard treatment of definitive concomitant reported in the RTOG-8501 trial and the recent phase III study with chemo-radiotherapy as definitive treatment (Herskovic et al, 1992; Bedenne et al, 2002; Minsky et al, 2002; Stahl et al, 2005). All results published with cisplatin-irinotecan regimen suggest that its efficacy is similar to that of a standard regimen with FU cisplatin for response rate and overall survival (Geh, 2002).

In the present study, no significant improvement of dysphagia was obtained by induction chemotherapy. However, in other studies using this combination of irinotecan-cisplatin in chemotherapy, a significant improvement of dysphagia was reported (Ilson et al, 1999; Tew et al, 2005). Ilson et al observed dysphagia resolution in $70 \%$ of patients after four chemotherapy courses. In our study, only $28.1 \%$ of patients reported dysphagia resolution after induction chemotherapy.

The development of regimens with induction chemotherapy has been significant; therefore, this regimen should have a similar efficacy as compared to the standard regimen. In contrast, the optimisation of the cisplatin-irinotecan-radiotherapy regimen could be potentially feasible. Epidermal growth factor receptor (EGFr) antibody or inhibitor could also increase the efficacy of the regimen: first by improving the therapeutic effect of irinotecan via EGFr antibodies as demonstrated in vitro (Prewett et al, 2002), second by the specific approach as demonstrated in head and neck cancer, by using radiation therapy and EGF receptor antibodies (Bonner et al, 2006; Pfister et al, 2006). The association cisplatinirinotecan-radiotherapy with EGFr antibody warrants further study. 
In the present study, planned treatment was performed in $69.8 \%$ of patients. This compliance is similar to $68 \%$ observed with $5 \mathrm{FU}$ and cisplatin in the RTOG 85-01 trial (Herskovic et al, 1992; Cooper et al, 1999). A severe adverse event was observed in 44 and $55.8 \%$ of patients in the RTOG $85-01$ study and our phase II, respectively. In the present study, two patients $(4.6 \%)$ presented life-threatening events compared with $20 \%$ in RTOG study. Haematotoxicity represented $62.2 \%$ of severe adverse events as in other regimens evaluated in patients with oesophageal cancer (Geh, 2002). In RTOG 85-01 trial, grade 3-4 esophagitis occurred in $33 \%$ of patients receiving chemo-radiotherapy (Herskovic et al, 1992). In present study only three patients (7\%) reported a grade 3-4 oesophageal toxicity. The incidence of clinical deep thrombosis was poor with only one case reported in our study.

\section{REFERENCES}

Ajani JA, Baker J, Pisters PW, Ho L, Mansfield PF, Feig BW, Charnsangavej C (2002) CPT-11 plus cisplatin in patients with advanced, untreated gastric or gastroesophageal junction carcinoma: results of a phase II study. Cancer 94: $641-646$

Bedenne L, Michel P, Bouche O, Triboulet JP, Conroy T, Pezet D, Roullet B, Seitz JF, Lacourt J, Milan C (2002) Randomized trial in locally advanced esophageal cancer: radiochemotherapy followed by surgery versus radiochemotherapy alone (FFCD9102). Proc Am Soc Clin Oncol 21, abstr 519

Bellisant E, Benichou J, Chastang C (1996) Application of the triangular test to phase II cancer clinical trials. Stat Med 9: 907-917

Bonner JA, Harari PM, Giralt J, Azarnia N, Shin DM, Cohen RB, Jones CU, Sur R, Raben D, Jassem J, Ove R, Kies MS, Baselga J, Youssoufian H, Amellal N, Rowinsky EK, Ang KK (2006) Radiotherapy plus cetuximab for squamous cell carcinoma of the head and neck. N Engl J Med 354: $567-578$

Coia LR, Minsky BD, Berkey BA, John MJ, Haller D, Landry J, Pisansky TM, Willett CG, Hoffman JP, Owen JB, Hanks GE (2000) Outcome of patients receiving radiation for cancer of the esophagus: results of the $1992-1994$ patterns of care study. J Clin Oncol 18: 455-462

Cooper JS, Guo MD, Herskovic A, Macdonald JS, Martenson Jr JA, Al-Sarraf M, Byhardt R, Russell AH, Beitler JJ, Spencer S, Asbell SO, Graham MV, Leichman LL (1999) Chemoradiation of locally advanced esophageal cancer: long-term follow-up of a prospective randomized trial (RTOG 85-01). JAMA 281: 1623-1627

Enzinger PC, Ilson DH, Kelsen DP (1999) Chemotherapy in esophageal cancer. Semin Oncol 26(Suppl 15): 12-20

Enzinger PC, Mayer RJ (2003) Esophageal cancer. $N$ Engl J Med 349: $2241-2252$

Geh JJ (2002) The use of chemoradiotherapy in oesophageal cancer. Eur J Cancer 38: $300-313$

Herskovic A, Martz K, al-Sarraf M, Leichman L, Brindle J, Vaitkevicius V, Cooper J, Byhardt R, Davis L, Emami B (1992) Combined chemotherapy and radiotherapy compared with radiotherapy alone in patients with cancer of the esophagus. N Engl J Med 326: 1593-1598

Ilson DH, Bains M, Kelsen DP, O’Reilly E, Karpeh M, Coit D, Rusch V, Gonen M, Wilson K, Minsky BD (2003) Phase I trial of escalating-dose irinotecan given weekly with cisplatin and concurrent radiotherapy in locally advanced esophageal cancer. J Clin Oncol 21: $2926-2932$

Ilson DH, Saltz L, Enzinger P, Huang Y, Kornblith A, Gollub M, O'Reilly E, Schwartz G, DeGroff J, Gonzalez G, Kelsen DP (1999) Phase II trial of weekly irinotecan plus cisplatin in advanced esophageal cancer. J Clin Oncol 17: $3270-3275$

Jemal A, Thomas A, Murray T, Thun M (2002) Cancer statistics. CA Cancer J Clin 52: $23-47$

Jones DR, Parker LA, Detterbeck FC, Egan TM (1999) Inadequacy of computed tomography in assessing patients with esophageal carcinoma after induction chemoradiotherapy. Cancer 85: 1026-1032

Keighley MRB (2003) Gastrointestinal cancers in Europe. Aliment Pharmacol Ther 18(Suppl 3): 7-30
In conclusion, cisplatin-irinotecan-radiotherapy regimen could be considered effective and its tolerance is similar to the standard treatment. Moreover, the regimen can be performed on an outpatient basis. Furthermore, chemotherapy induction and the possibility to optimise the association with EGFr antibody warrants further studies with the combination irinotecancisplatin and radiotherapy in patients with oesophageal cancer.

\section{ACKNOWLEDGEMENTS}

We thank Richard Medeiros, Rouen University Hospital Medical Editor, for his valuable advice in editing the manuscript and Corina Oprea, Aventis, for her assistance. This study was supported by grants from Aventis.

Kelsen DP, Heelan R, Coonley C, Bains M, Martini N, Hilaris B, Golbey RB (1983) Clinical and pathological evaluation of response to chemotherapy in patients with oesophageal carcinoma. Am J Clin Oncol 6: 539-546

Koukourakis MI, Bizakis JG, Skoulakis CE, Kyrmizakis D, Giatromanolaki A, Papadakis CE, Prokopakis E, Amanakis Z, Hellidonis ES (1999) Combined irinotecan, docetaxel and conventionally fractionated radiotherapy in locally advanced head and neck cancer. A phase I dose escalation study. Anticancer Res 19: 2305-2309

Minsky BD, Pajak TF, Ginsberg RJ, Pisansky TM, Martenson J, Komaki R, Okawara G, Rosenthal SA, Kelsen DP (2002) INT 0123 (Radiation Therapy Oncology Group 94-05) Phase III trial of combined-modality therapy for esophageal cancer: high-dose versus standard dose radiation therapy. J Clin Oncol 20: 1167-1174

Ogilvie AL, Dronfield MW, Ferguson R, Atkinson M (1982) Palliative intubation of esophagogastric neoplasms at fibreoptic endoscopy. Gut 23: $1060-1067$

Pfister DG, Su YB, Kraus DH, Wolden SL, Lis E, Aliff TB, Zahalsky AJ, Lake S, Needle MN, Shaha AR, Shah JP, Zelefsky MJ (2006) Concurrent cetuximab, cisplatin, and concomitant boost radiotherapy for locoregionally advanced, squamous cell head and neck cancer: a pilot phase II study of a new combined-modality paradigm. J Clin Oncol 24: 1072-1078

Poplin EA, Jacobson J, Herskovic A, Panella TJ, Valdivieso M, Hutchins LF, Macdonald JS (1996) Evaluation of multimodality treatment of locoregional esophageal carcinoma by Southwest Group 9060. Cancer 78: $1851-1856$

Prewett MC, Hooper AT, Bassi R, Ellis LM, Waksal HW, Hicklin DJ (2002) Enhanced antitumor activity of anti-epidermal growth factor receptor monoclonal antibody IMC-C225 in combination with irinotecan (CPT-11) against human colorectal tumor xenografts. Clin Cancer Res 8: 994-1003

Seitz JF, Giovannini M, Padaut-Cesana J, Fuentes P, Giudicelli R, Gauthier AP, Carcassonne Y (1990) Inoperable nonmetastatic squamous cell carcinoma of the esophagus managed by concomitant chemotherapy (5fluorouracil and cisplatin) and radiation therapy. Cancer 66: 214-219

Stahl M, Stuschke M, Lehmann N, Meyer HJ, Walz MK, Seeber S, Klump B, Budach W, Teichmann R, Schmitt M, Schmitt G, Franke C, Wilke H (2005) Chemoradiation with and without surgery in patients with locally advanced squamous cell carcinoma of the esophagus. J Clin Oncol 23: $2310-2317$

Takeda K, Negoro S, Kudoh S, Okishio K, Masuda N, Takada M, Tanaka M, Nakajima T, Tada T, Fukuoka M (1999) Phase I/II study of weekly irinotecan and concurrent radiation therapy for locally advanced nonsmall cell lung cancer. Br J Cancer 79: $1462-1467$

Tamura K, Takada M, Kawase I, Tada T, Kudoh S, Okishio K, Fukuoka M, Yamaoka N, Fujiwara Y, Yamakido M (1997) Enhancement of tumor radio-response by irinotecan in human lung tumor xenografts. Jpn J Cancer Res 88: $218-223$

Tew WP, Minsky B, Bains M, Rizk N, Rusch V, Kelsen DP, Shah M, Kepler $\mathrm{S}$, Gonen M, Ilson DH (2005) Phase II trial of preoperative combined modality therapy for esophageal carcinoma: induction cisplatinirinotecan followed by concurrent cisplatin-irinotecan and radiotherapy. Proc Am Soc Clin Oncol 25, Abs 4017 